\title{
Intrarenal Dynamics in the Pathogenesis and Prevention of Acute Urate Nephropathy
}

\author{
John D. Conger and SANDOR A. FALK \\ From the Departments of Medicine, Pathology, and Physiology, University of Colorado Medical \\ Center and Veterans Administration Hospital, Denver, Colorado 80220
}

\begin{abstract}
A в S T RACT Tubular fluid flow, urine osmolality, and $\mathrm{pH}$ were selectively altered to determine the relative protective roles of these factors in a rat model of acute urate nephropathy. Various prehyperuricemic conditions were established in five groups of animals: $(a)$ normopenic Wistar rats given no pretreatment (Group I); (b) Wistar rats given acetazolamide, $20 \mathrm{mg} / \mathrm{kg}$, and isotonic $\mathrm{NaHCO}_{3}$ to produce urine alkalinization (Group II); (c) Wistar rats in which a moderate diuresis, similar to that observed in Group II but without urine alkalinization, was induced with furosemide, $2 \mathrm{mg} / \mathrm{kg}$ (Group III); (d) Wistar rats in which a high-flow solute diuresis was induced with furosemide, $15 \mathrm{mg} / \mathrm{kg}$ (Group IV); $(e$ ) Brattleboro rats, homozygous for pituitary diabetes insipidus, that had a spontaneous high-flow water diuresis (Group V). A comparable level of hyperuricemia $(19.4 \pm 2.2 \mathrm{mg} / 100 \mathrm{ml})$ was achieved in all animals with intravenous urate infusion. Clearance and micropuncture studies were performed before and $1 \mathrm{~h}$ after induction of hyperuricemia. Group I rats had mean falls in renal plasma flow and glomerular filtration rate of 83 and $86 \%$, respectively; nephron filtration rate decreased $66 \%$, and tubular and microvascular pressures increased twofold. In Group II there were 45 and $47 \%$ declines in renal plasma flow and glomerular filtration rate, respectively, a $66 \%$ fall in nephron filtration rate, and a $30 \%$ increase in tubular and vascular pressures. Moderate amounts of urate were seen in the kidneys. Group III had changes in renal function identical to Group II suggesting that the moderate prehyperuricemic diuresis in the latter group and not urine alkalinization produced the partial protection observed. Groups IV
\end{abstract}

Portions of this study appeared in abstract form in the Proceedings of the 8th Annual Meeting of the American Society of Nephrology, Washington, D. C., 25-26 November 1975, 8: 60 .

Received for publication 8 November 1976 and in revised form 7 January 1977. and $\mathrm{V}$ were completely and comparably protected with renal function studies unchanged from controls.

It is concluded that high tubular fluid flow, whether induced by a solute or water diuresis, is the primary mechanism of protection in acute urate nephropathy. At most, urine alkalinization plays a minor preventive role.

\section{INTRODUCTION}

It is an established clinical observation that abrupt renal failure can occur as the result of uric acid and urate deposition within the kidney (1-8). Although hyperuricemia per se is considered to be the necessary and immediate cause of this disorder, the relatively poor correlation between the plasma urate level and degree of renal dysfunction (5-9) suggests that additional factors must modify the rate of uric acid and urate precipitation and the severity of consequent renal damage. In vitro studies have shown the importance of solvent $\mathrm{pH}$ and ionic strength in determining the solubility of uric acid and its sodium salt (10-12). These findings have been the basis for the use of forced diuresis and urine alkalinization in the treatment of acute urate nephropathy (13). However, neither the actual mechanism of protection nor the relative efficacy of these two modalities of management have been determined, since the critical intrarenal factors that lead to uric acid and urate deposition in the in vivo setting have not been clearly established.

An animal model recently developed in our laboratory (14) seemed to lend itself to an investigation of the roles of intrarenal dynamics in the pathogenesis and prevention of acute urate nephropathy. The effects of changes in tubular fluid flow rate, urine $\mathrm{pH}$, and urine osmolality on the magnitude of renal damage from acute hyperuricemia were evaluated in the rat with clearance, micropuncture, and morphologic techniques. 
The results indicated that high tubular fluid flow rate induced by either a solute or water diuresis was the primary factor preventing the development of acute urate nephropathy. Urine alkalinization had no detectable protective effect in this model.

\section{METHODS}

The model of acute urate nephropathy is described in detail in a previous report (14). Male Wistar rats and Brattleboro rats, homozygous for hypothalamic diabetes insipidus, and weighing 250-300 g, were fasted overnight but permitted free access to water. They were anesthetized with pentobarbital $(60 \mathrm{mg} / \mathrm{kg}$ i.p.) and supplemental doses of pentobarbital $(5-10 \mathrm{mg} / \mathrm{kg}$ i.v.) were given as necessary during the study. After anesthesia oxonic acid $(250 \mathrm{mg} / \mathrm{kg})$, a uricase inhibitor, was given intraperitoneally. The rats were placed on a heated surgical table $\left(37^{\circ} \mathrm{C}\right)$ and prepared for clearance and micropuncture experiments as previously outlined (14). Polyethylene catheters were placed in the right external jugular vein, left renal vein via the right femoral vein, right femoral artery, and the ureter of the left kidney which had been positioned for micropuncture. The femoral artery catheter was attached to a pressure transducer (model 267B, Hewlett-Packard Co., Palo Alto, Calif.) and the blood pressure recorded on a Hewlett-Packard recorder (model 7702B). Isotonic Ringer's solution containing inulin, para-aminohippurate (PAH) ${ }^{1}$ and oxonic acid was infused via the jugular vein catheter at $50 \mu \mathrm{l} / \mathrm{kg}$ per min in Wistar rats. For Brattleboro rats the infusion rate was adjusted to match spontaneous urine flow rate as estimated from the 24 -h volume before study. The average rate of delivery into these Brattleboro rats was 150 $\pm 30 \mu \mathrm{l} / \mathrm{min}$. The concentrations of inulin and PAH were sufficient to give plasma levels of $50-100 \mathrm{mg} / 100 \mathrm{ml}$ and $2-4 \mathrm{mg} / 100 \mathrm{ml}$, respectively. Oxonic acid content was adjusted to deliver $2 \mathrm{mg} / \mathrm{kg}$ per $\mathrm{min}$. $1 \mathrm{~h}$ before the experiments, $1 \mathrm{ml}$ of blood was removed from the femoral artery and replaced with an equal volume of isotonic Ringer's solution. Aliquots of this blood equal in volume to samples taken for inulin, $\mathrm{PAH}$, and urate analysis were returned to the animal during the study to maintain stability of hematocrit.

To determine the effects of tubular fluid flow rate, urine $\mathrm{pH}$, and osmolality on the severity of kidney damage from hyperuricemia, the rats were divided into five groups each receiving a different treatment before hyperuricemia was induced (Table I). Group I included Wistar rats given no pretreatment. Group II included Wistar rats in which urine alkalinization was produced by giving acetazolamide intravenously $(20 \mathrm{mg} / \mathrm{kg}$ per $\mathrm{h})$ and a maintenance infusion of isotonic sodium bicarbonate. The latter was given at the same rate and with the same inulin, PAH, and oxonic acid content as the isotonic Ringer's solution described above. Group III contained Wistar rats in which a diuresis quantitatively similar to that observed in Group II was established, but without a change in urine $\mathrm{pH}(\mathrm{UpH})$. This was accomplished by giving intravenous furosemide, $2.0 \mathrm{mg} / \mathrm{kg}$. Group IV included Wistar rats in which a high flow solute diuresis was induced by the intravenous injection of furosemide ( $15 \mathrm{mg} / \mathrm{kg}$ ). Group V contained Brattle-

${ }^{1}$ Abbreviations used in this paper: GFR, glomerular filtration rate; $\mathrm{PAH}$, para-aminohippurate; $\mathrm{P}_{\text {urate, plasma urate }}$ concentration; RPF, renal plasma flow; SNGFR, single nephron GFR; Uosm, urine osmolality; $\mathrm{UpH}$, urine $\mathrm{pH}$; $\mathrm{U}_{\text {urate }}$, urinary urate concentration; $\mathrm{V}$, urine flow rate.
TABLE I

Description of Animal Groups Studied
Group I

Group II

Group III

Group IV

Group V
Normopenic Wistar rats, no pretreatment

Wistar rats, alkaline urine, moderate diuresis Wistar rats, acid urine, moderate diuresis Wistar rats, high-flow solute diuresis Brattleboro rats, high-flow water diuresis boro rats with a spontaneous high-flow water diuresis. They were given no specific treatment except for the adjustment in Ringer's solution infusion rate described above. Urine losses were replaced with equal volumes of isotonic Ringer's solution in Groups III and IV and with isotonic sodium bicarbonate in Group II.

30 min after beginning the selected pretreatment, all animals were subjected to the following experimental protocol.

Control studies. Samples of femoral artery $(0.4 \mathrm{ml})$ and renal vein blood $(0.1 \mathrm{ml})$ were obtained between two timed $50-\mu l$ collections of urine. Inulin, PAH, and urate concentrations were determined on blood and urine samples. Osmolality and pH were measured on urine samples. Timed collections of tubular fluid were obtained from four or five last proximal tubular loops with oil-filled micropipettes (8-10 $\mu \mathrm{m}$ OD) as previously described (15). Using a servo-null pressure apparatus (Instrumentation for Physiology and Medicine, San Diego, Calif.), hydrostatic pressures were measured in 5-10 proximal tubules, 3-5 efferent arterioles, and 5-10 peritubular capillaries.

Experimental studies. After the control measurements were completed, lithium urate ${ }^{2}$ prepared by dissolving uric acid in a warmed solution of saturated lithium carbonate and adjusted to $\mathrm{pH}$ of 7.4 , was injected into the jugular catheter over $5 \mathrm{~min}$. The total dose was $300 \mathrm{mg} / \mathrm{kg}$ delivered in a volume of $3 \mathrm{ml}$. Femoral artery blood $(0.3 \mathrm{ml})$ for urate concentration was obtained $3 \mathrm{~min}$ after the injection, the time when urate achieved its highest level in the plasma. $1 \mathrm{~h}$ later repeat femoral artery and renal vein blood and ureteral urine collections for inulin, PAH, urate, osmolality, and $\mathrm{pH}$ were obtained. Repeat tubular fluid collections were made from four to five new last proximal tubular sites. During collection, the intratubular pressure existing in that tubule was monitored with a pressure pipette positioned just distal to the oil block. Fluid collection was controlled to maintain pressure constant. Hydrostatic pressures were remeasured in proximal tubules, efferent arterioles, and peritubular capillaries.

Morphologic studies. A detailed description of both the gross and microscopic lesions in this model has been reported previously (14). In this study comparisons were made under a dissecting microscope of kidneys, sectioned in planes parallel to their long axes. Each kidney was photographed to document the degree of uric acid and urate deposition.

Analytical methods. Plasma and urine inulin and PAH were measured with a Technicon AutoAnalyzer (Technicon Instruments Corp., Tarrytown, N. Y.). Urate content was measured by a colorimetric uricase method (American Monitor Corp., Indianapolis, Ind.) and urine osmolality determined with a model 3L osmometer (Advanced Instru-

${ }^{2}$ In a prior set of control studies (14) there were no measurable effects of lithium per se on water handling or other parameters of renal function at $1 \mathrm{~h}$ with the doses employed in the present experiments. 
TABLE II

Clearance Results before and after Urate Infusion

\begin{tabular}{|c|c|c|c|c|c|c|c|c|c|c|c|c|c|c|c|c|c|c|}
\hline \multirow[b]{2}{*}{ Group } & & \multicolumn{2}{|c|}{ BP } & \multicolumn{2}{|c|}{$P_{\text {urate }}$} & \multicolumn{2}{|c|}{ RPF } & \multicolumn{2}{|c|}{ GFR } & \multicolumn{2}{|c|}{ v } & \multicolumn{2}{|c|}{$\mathrm{U}_{\text {urate }}$} & \multicolumn{2}{|c|}{ Uosm } & \multicolumn{2}{|c|}{$\mathrm{UpH}$} & \multirow{2}{*}{$\frac{\text { Hct }}{\text { Cont Exp }}$} \\
\hline & & Con & Exp & Con & Exp & Cont & $\operatorname{Exp}$ & Cont & Exp & Cont & $\operatorname{Exp}$ & Cont & $\operatorname{Exp}$ & Con & Exp & Cont & Exp & \\
\hline & & & & $m g / 1$ & $00 \mathrm{ml}$ & & & & & & & $m g / l$ & $0 \mathrm{ml}$ & $\operatorname{mos} n$ & Uliter & & & $\%$ \\
\hline \multirow[t]{3}{*}{ I $\quad($} & Mean & 117 & 118 & 1.2 & 20.1 & 3186 & 546 & 860 & 116 & 11.3 & 4.2 & 24.3 & 142.2 & 961 & 665 & 5.5 & 6.0 & 47 \\
\hline & SD & 9 & 13 & 0.6 & 3.1 & 926 & 2.54 & 212 & 42 & 4.8 & 2.2 & 5.1 & 21.0 & 166 & 77 & 0.3 & 0.1 & 3 \\
\hline & $P$ & \multicolumn{2}{|c|}{ NS } & \multicolumn{2}{|c|}{$<0.001$} & \multicolumn{2}{|c|}{$<0.005$} & \multicolumn{2}{|c|}{$<0.001$} & \multicolumn{2}{|c|}{$<0.005$} & \multicolumn{2}{|c|}{$<0.001$} & \multicolumn{2}{|c|}{$<0.02 .5$} & \multicolumn{2}{|c|}{$<0.05$} & NS \\
\hline \multirow[t]{3}{*}{ II (6) } & Mean & 114 & 119 & 1.8 & 17.3 & 3614 & 1982 & 1019 & 538 & 30.9 & 6.6 & 17.1 & 58.9 & 502 & 495 & 7.9 & 7.6 & 46 \\
\hline & SD & 10 & 6 & 0.4 & 2.4 & 399 & 426 & 159 & 293 & 11.0 & 2.0 & 9.3 & 4.1 & 28 & 61 & 0.2 & 0.3 & 7 \\
\hline & $P$ & \multicolumn{2}{|c|}{ NS } & \multicolumn{2}{|c|}{$<0.001$} & \multicolumn{2}{|c|}{$<0.01$} & \multicolumn{2}{|c|}{$<0.01$} & \multicolumn{2}{|c|}{$<0.001$} & \multicolumn{2}{|c|}{$<0.001$} & \multicolumn{2}{|c|}{ NS } & \multicolumn{2}{|c|}{ NS } & NS \\
\hline \multirow[t]{3}{*}{ III (6) } & Mean & 116 & 116 & 1.4 & 18.3 & 3558 & 1634 & 944 & 528 & 38.3 & 16.7 & 18.9 & 48.3 & 359 & 356 & 5.8 & 6.1 & 53 \\
\hline & SD & 13 & 15 & 0.5 & 3.5 & 469 & 277 & 139 & 138 & 4.9 & 10.4 & 5.4 & 6.7 & 25 & 25 & 0.1 & 0.1 & \\
\hline & $P$ & & S & & 001 & & & & & & & & & & & $<0.0$ & & NS \\
\hline IV (6) & Mean & 119 & 124 & 1.4 & 21.2 & 3691 & 3611 & 997 & 975 & 163.4 & 156.3 & 12.6 & 25.5 & 363 & 423 & 6.0 & 5.9 & 47 \\
\hline & SD & 16 & 11 & 0.8 & 6.5 & 252 & 163 & 189 & 170 & 47.1 & 40.8 & 7.1 & 10.0 & 47 & 57 & 0.3 & 0.3 & \\
\hline & $P$ & & is & & 001 & & & & & & & & & & & NS & & NS \\
\hline V (5) & Mean & 109 & 116 & 1.5 & 18.1 & 2790 & 2402 & 834 & 706 & 106.8 & 126.7 & 5.4 & 17.2 & 228 & 236 & 6.0 & 6.2 & 42 \\
\hline & SD & 18 & 18 & 0.9 & 3.2 & 550 & 665 & 197 & 228 & 47.8 & 47.2 & 1.5 & 5.8 & 27 & 5.5 & 0.5 & 0.5 & \\
\hline & $P$ & & IS & & 001 & & & & & & & & & & & NS & & NS \\
\hline
\end{tabular}

Abbreviations: Cont, control period before urate infusion; Exp, experimental period $1 \mathrm{~h}$ after urate injection; BP, mean arterial blood pressure; Hct, arterial blood hematocrit. Numbers in parentheses indicates the number of animals studied.

* $P_{\text {urate }}$ in experimental period was obtained at 3 min after urate infusion.

ments, Inc., Needham Heights, Mass.). A radiometer Copenhagen $\mathrm{pH}$ meter 26 (The London Co., Cleveland, Ohio) was used to measure urine $\mathrm{pH}$. Tubular fluid inulin was estimated by the micromethod of Vurek and Pegram (16) as modified for this laboratory (17).

The paired $t$ test was used to compare results between control and experimental phase of the studies and the unpaired $t$ test was used to compare the data between groups of animals. Regression analysis was used to determine correlation between parameters. Data throughout are expressed as means $\pm 1 \mathrm{SD}$.

\section{RESULTS}

Normopenic rats without pretreatment (Group I). The clearance and micropuncture data are shown in Tables II and III, respectively. Before urate infusion, urine flow rate was $11.3 \pm 4.8 \mu \mathrm{l} / \mathrm{min}$, urine osmolality (Uosm) was $961 \pm 166 \mathrm{mosmol} / \mathrm{liter}$, and $\mathrm{UpH}$ was $5.5 \pm 0.3$. After urate infusion, plasma urate concentration $\left(\mathrm{P}_{\text {urate }}\right)$ rose from $1.2 \pm 0.6$ to $20.1 \pm 3.1$ $\mathrm{mg} / 100 \mathrm{ml}(P<0.001)$. Associated with this level of hyperuricemia were declines in renal plasma flow (RPF) and glomerular filtration rate (GFR) of 83 and $86 \%$, respectively, and of urine flow rate of $63 \%$ (Fig. 1). Single nephron GFR (SNGFR) fell from 29.7 \pm 11.5 to $10.1 \pm 3.7 \mathrm{nl} / \mathrm{min}$ and proximal tubule absolute reabsorption had a fractionally similar decrease from $15.6 \pm 6.6$ to $5.1 \pm 2.8 \mathrm{nl} / \mathrm{min}$ (both $P<0.005$ ). Hydrostatic pressures in proximal tubules, efferent arterioles, and peritubular capillaries increased twofold. The kidneys of these rats were swollen with moderate external pallor. The cut sections showed dense deposits of yellow-white material from the juxtamedullary zone to the tip of the papillae. ${ }^{3} \mathrm{~A}$ trace amount of crystalline material was present in the cortex. A representative kidney from Group I rats is shown in Fig. 2A.

Urine alkalinization (Groups II and III). At the time of urate infusion $\mathrm{UpH}$ was $7.9 \pm 0.2$ in Group II rats which was $43 \%$ higher than the comparable value in Group I $(P<0.001)$. With the use of acetazolamide to produce urine alkalinization, there was a moderate diuresis. Urine flow rate was $30.0 \pm 11.0$ $\mu \mathrm{l} / \mathrm{min}$ which was higher than that of the untreated animals $(P<0.005)$. After urate infusion the rise in plasma urate from $1.8 \pm 0.4$ to $17.3 \pm 2.4 \mathrm{mg} / 100 \mathrm{ml}$ was similar to that of Group I. Despite the alkaline UpH, renal function declined significantly after induction of hyperuricemia. RPF fell to 55\% and GFR to $43 \%$ of their control values (both $P<0.001$ ). Urine flow rate decreased to $6.6 \pm 2.0 \mu \mathrm{l} / \mathrm{min}(P<0.001)$. SNGFR fell from $29.4 \pm 8.3 \mathrm{nl} / \mathrm{min}$ to $11.4 \pm 2.2 \mathrm{nl} / \mathrm{min}(P$ $<0.01)$ and proximal tubule absolute reabsorption was reduced from $11.8 \pm 5.4$ to $4.4 \pm 0.7 \mathrm{nl} / \mathrm{min}(P$ $<0.02$ ). Proximal tubule hydrostatic pressure was increased by 50 percent $(P<0.01)$; efferent arteriole and peritubular capillary hydrostatic pressures rose by 27 and $30 \%$, respectively (both $P<0.005$ ). While

${ }^{3}$ In a previous study the deposits were found to be crystals with an appearance compatible with uric acid and urate salts. These were located within collecting ducts and vasa recti. The possibility that some of the deposits represented carbonate salts was excluded by demonstrating a lack of deposits when infusions of lithium carbonate equimolar to lithium urate were substituted for the latter (14). 
TABLE III

Micropuncture Results before and after Urate Infusion

\begin{tabular}{|c|c|c|c|c|c|c|c|c|c|c|c|}
\hline \multirow[b]{2}{*}{ Group } & & \multicolumn{2}{|c|}{ SNGFR } & \multicolumn{2}{|c|}{$\mathrm{Jv}$} & \multicolumn{2}{|c|}{$\mathrm{P}_{\mathrm{PT}}$} & \multicolumn{2}{|c|}{$P_{\mathrm{VA} A}$} & \multicolumn{2}{|c|}{$\mathrm{Pc}$} \\
\hline & & Cont & Exp & Cont & $\operatorname{Exp}$ & Cont & $\operatorname{Exp}$ & Cont & Exp & Cont & $\operatorname{Exp}$ \\
\hline & & & $n l / t$ & & & & & & & & \\
\hline \multirow[t]{3}{*}{ I } & Mean & 29.7 & 10.1 & 15.6 & 5.1 & 10.6 & 26.1 & 14.2 & 26.4 & 10.9 & 18.1 \\
\hline & SD & 11.5 & 3.7 & 6.6 & 2.8 & 3.7 & 5.1 & 2.6 & 2.3 & 2.3 & 1.0 \\
\hline & $P$ & \multicolumn{2}{|c|}{$<0.005$} & \multicolumn{2}{|c|}{$<0.005$} & \multicolumn{2}{|c|}{$<0.005$} & \multicolumn{2}{|c|}{$<0.001$} & \multicolumn{2}{|c|}{$<0.001$} \\
\hline \multirow[t]{3}{*}{ II (6) } & Mean & 29.4 & 11.4 & 11.8 & 4.4 & 11.0 & 16.1 & 15.5 & 19.7 & 9.9 & 12.9 \\
\hline & SD & 8.3 & 2.2 & 5.4 & 0.7 & 1.5 & 3.9 & 1.5 & 2.8 & 1.6 & 1.6 \\
\hline & $P$ & \multicolumn{2}{|c|}{$<0.01$} & \multicolumn{2}{|c|}{$<0.02$} & \multicolumn{2}{|c|}{$<0.01$} & \multicolumn{2}{|c|}{$<0.005$} & \multicolumn{2}{|c|}{$<0.005$} \\
\hline \multirow[t]{3}{*}{ III (6) } & Mean & 26.4 & 14.5 & 14.6 & 8.7 & 10.6 & 15.8 & 15.7 & 20.3 & 10.5 & 12.6 \\
\hline & SD & 9.2 & 5.2 & 5.6 & 2.0 & 1.6 & 2.9 & 0.8 & 3.2 & 0.8 & 1.1 \\
\hline & $P$ & \multicolumn{2}{|c|}{$<0.02$} & \multicolumn{2}{|c|}{$<0.03$} & \multicolumn{2}{|c|}{$<0.01$} & \multicolumn{2}{|c|}{$<0.05$} & \multicolumn{2}{|c|}{$<0.01$} \\
\hline \multirow[t]{3}{*}{ IV (6) } & Mean & 25.4 & 26.8 & 12.6 & 14.3 & 10.3 & 11.7 & 15.3 & 16.3 & 10.7 & 11.6 \\
\hline & SD & 6.9 & 7.5 & 3.8 & 3.8 & 1.3 & 2.1 & 1.4 & 1.1 & 0.8 & 1.0 \\
\hline & $P$ & \multicolumn{2}{|c|}{ NS } & \multicolumn{2}{|c|}{ NS } & \multicolumn{2}{|c|}{ NS } & \multicolumn{2}{|c|}{ NS } & \multicolumn{2}{|c|}{ 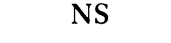 } \\
\hline \multirow[t]{3}{*}{ V (5) } & Mean & 29.8 & 25.9 & 14.6 & 10.2 & 10.4 & 10.6 & 14.3 & 15.0 & 11.6 & 10.6 \\
\hline & SD & 2.5 & 5.6 & 3.4 & 3.1 & 1.2 & 0.8 & 1.7 & 0.9 & 1.1 & 1.4 \\
\hline & $P$ & \multicolumn{2}{|c|}{ NS } & \multicolumn{2}{|c|}{$<0.01$} & \multicolumn{2}{|c|}{ NS } & & & & \\
\hline
\end{tabular}

Abbreviations: Jv, proximal tubule absolute reabsorption; $\mathrm{P}_{\mathrm{PT}}$, proximal tubule hydrostatic pressure; $\mathrm{P}_{\mathrm{EA}}$, efferent arteriole hydrostatic pressure; $\mathrm{Pc}$, peritubular capillary hydrostatic pressure. Numbers in parentheses represent the number of animals studied.

the fall in renal function in Group II was highly significant when compared to prehyperuricemic parameters, the declines in RPF and GFR and elevations of tubular and vascular pressures were less than those in Group I animals (all $P<0.01$ ).

The cut section of a kidney from a Group II rat is shown in Fig. 2B. There was a moderate amount of crystal deposition in the medulla and papilla, but less than that noted in Group I kidneys.

To determine whether the partial protection of renal function observed in Group II rats was a consequence of urine alkalinization or the moderate diuresis present before urate infusion, the results were compared to those in Group III. The latter group had a prehyperuricemic urine flow rate of $38.3 \pm 4.9 \mu \mathrm{l} / \mathrm{min}$ which was not different from that for Group II, but the $\mathrm{UpH}$ of $5.8 \pm 0.1$ was significantly more acid than that of Group II $(P<0.001)$ and similar to that of Group I. After urate infusion, the decline in renal function in Group III was nearly identical to that of Group II (Fig. 1). In the former animals RPF fell from $3,588 \pm 460$ to $1,634 \pm 277 \mu \mathrm{l} / \mathrm{min}$. In the latter group the same parameter was reduced from 3,614 \pm 300 to $1,982 \mu \mathrm{l} / \mathrm{min}$. Likewise, the fall in GFR in Group III ( $944 \pm 139$ to $528 \pm 138 \mu \mathrm{l} / \mathrm{min})$ was the same as that of Group II $(1,019 \pm 159$ to $538 \pm 293 \mu \mathrm{l} / \mathrm{min})$. The decreases in urine flow rate (V) also were not different between the two groups. When comparing micropuncture results, there was a close parallel with the clearance studies. There were like declines in SNGFR and similar increases in micropressure measurements for the two groups.

The cut sections of Group III kidneys, as illustrated in Fig. 2C, had a moderate amount of urate deposi-

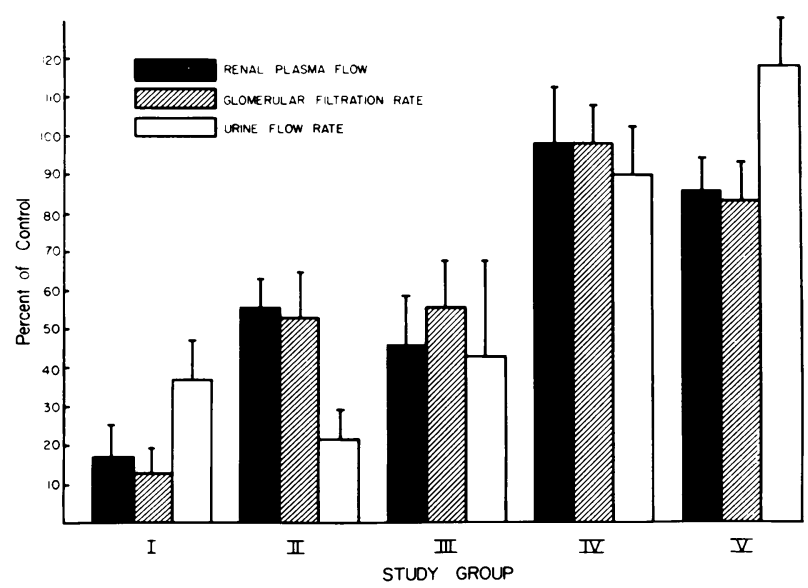

Figure 1 Percent of control values of renal plasma flow, glomerular filtration rate, and urine flow rate in the five groups of rats after induction of comparable levels of hyperuricemia. I, no pretreatment; II, urine alkalinization and moderate diuresis; III, acid urine and moderate diuresis; IV, high-flow solute diuresis; and V, high-flow water diuresis. 

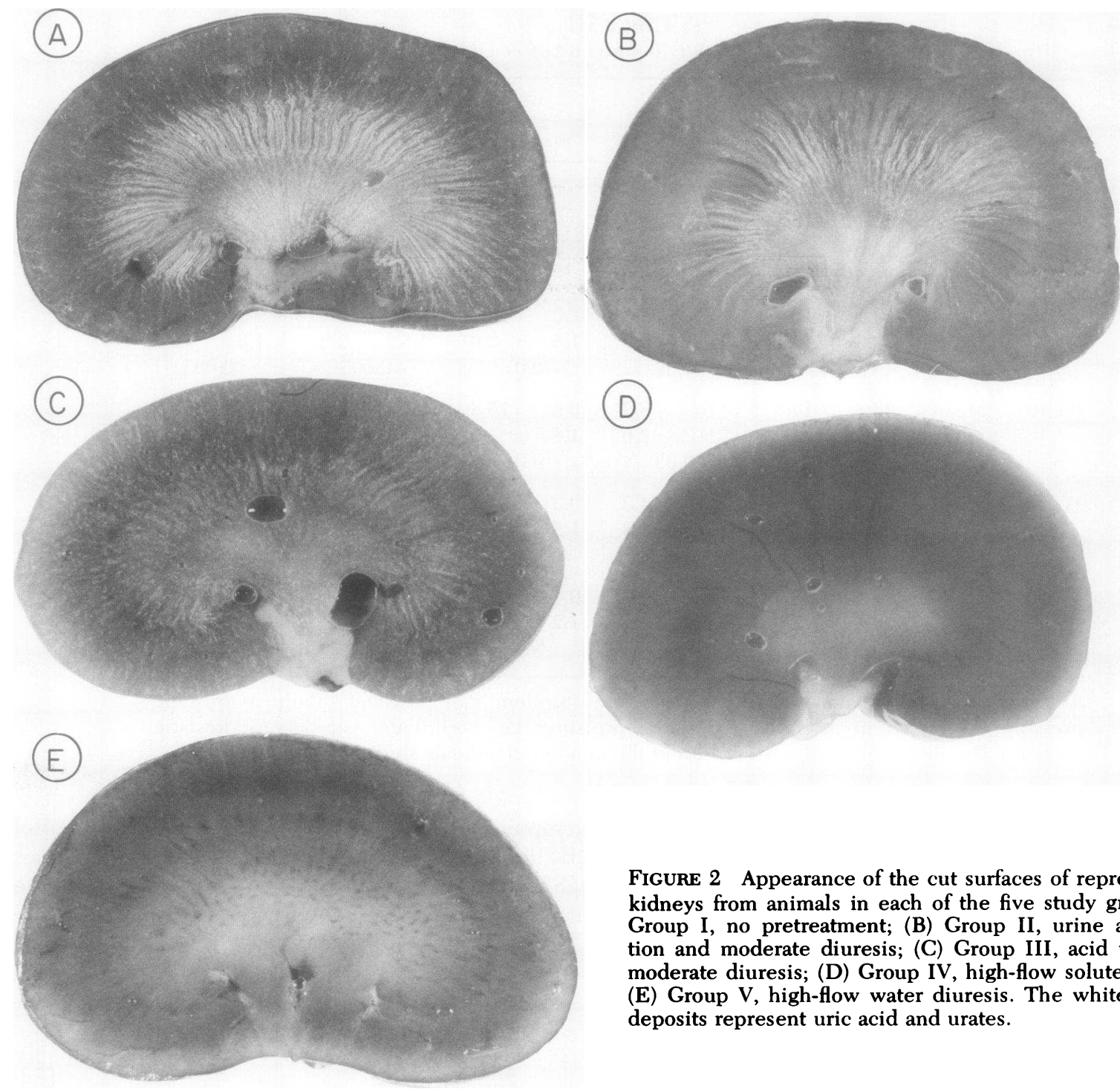

FIGURE 2 Appearance of the cut surfaces of representative kidneys from animals in each of the five study groups: (A) Group I, no pretreatment; (B) Group II, urine alkalinization and moderate diuresis; (C) Group III, acid urine and moderate diuresis; (D) Group IV, high-flow solute diuresis; (E) Group V, high-flow water diuresis. The white-streaked deposits represent uric acid and urates.

tion similar in density to that seen in Group II animals.

High-flow solute diuresis (Group IV). In these animals, $\mathrm{V}$ was $163.4 \mu \mathrm{l} / \mathrm{min}$ before induction of hyperuricemia, which was 15 times the corresponding value in Group I. Uosm was less than half, but $\mathrm{UpH}$ was acid and not different from that of the untreated rats. The change in $P_{\text {urate }}$ after infusion was similar to that in Group $I$, increasing from $1.4 \pm 0.8$ to $21.2 \pm 6.5$ $\mathrm{mg} / 100 \mathrm{ml}(P<0.001)$. Despite the rise in plasma urate, renal function did not change. RPF, GFR, and $\mathrm{V}$ all remained at control levels as show in Fig. 1. Micropuncture measurements also continued at control levels.

The kidneys of Group IV rats had a normal external appearance. In three of the six animals there were occasional streaks of uric acid in the papillae, otherwise there were no abnormalities detected on cut sections (Fig. 2D).

High-flow water diuresis (Group V). In the Brattleboro rats the prehyperuricemic urine flow rate was $106.8 \pm 47.8 \mu \mathrm{l} / \mathrm{min}$, the Uosm $228 \mathrm{mosmol} / \mathrm{liter}$ and UpH 6.0 \pm 0.5 . The Uosm was significantly lower than any other group $(P<0.01)$. $\mathrm{UpH}$ was similar to Group I. With urate infusion, the plasma level rose to 18.1 $\pm 3.2 \mathrm{mg} / 100 \mathrm{ml}$, similar to that in Group I. As in Group IV there was no measurable change in RPF, GFR, or V after hyperuricemia. Except for a slight fall in proximal reabsorption, none of the micropuncture parameters varied significantly between the control and experimental periods.

There were rare patchy crystalline deposits noted in 
the kidneys of two rats. In three of five animals no crystals were seen (Fig. 2E).

\section{DISCUSSION}

The predominant abnormalities in this model of hyperuricemia with acute renal failure (Group I) were tubular and vascular obstruction resulting in marked declines of renal blood flow and glomerular filtration (14). The underlying pathologic lesion was the deposition within collecting ducts, deep cortical, and medullary vessels of uric acid and urate crystals. The biochemical factors that predispose to urate deposition are in large part related to the solubility characteristics of this substance according to in vitro studies (10-12). Plasma urate is present primarily as the sodium salt and the normally measured levels are relatively close to the in vitro determined solubility limit (10-12). A number of properties peculiar to the renal environment enhance the tendency to urate precipitation within this organ. These include active secretion of urate $(18,19)$, the renal concentrating mechanism, and the $\mathrm{pH}$ of tubular fluid relative to the $\mathrm{pKa}$ of uric acid. The effects of these factors are to increase the concentration of urate in the tubular system and convert the major fraction of the ionized salt form to the less soluble acid form at $\mathrm{pH}$ levels achieved beyond the distal tubule. ${ }^{4}$ Even at normal filtered levels of urate, conditions are frequently such that the solubility of uric acid as determined by in vitro measurements is approached or exceeded in the final urine (10). Based on these measurements, it is not surprising that marked hyperuricemia, as occurs in neoplastic diseases and as was mimicked by the present experiments, should lead to deposition of urates and uric acid in the kidney. On the other hand, there is considerable clinical evidence that despite such marked hyperuricemia the degree of renal dysfunction that results is highly variable (5-9). For this reason the present set of experiments was designed to examine the importance of dynamic factors within the kidney in the pathogenesis and prevention of acute urate nephropathy. The roles of tubular fluid flow rate, $\mathrm{UpH}$, and Uosm were studied by selectively altering these parameters in a setting of relatively constant hyperuricemia.

$\mathrm{V}$ was of greatest significance in determining the severity of urate deposition and renal function impairment. Both the high-dose furosemide and Brattleboro rats had complete protection from the renal damage of hyperuricemia. High urinary flow rates were unique to these two groups of animals. Intermediate preservation of kidney function was associated with

\footnotetext{
${ }^{4}$ The pKa of uric acid is 5.7 (9). Distal tubular fluid $\mathrm{pH}$ in normal hydropenic rats averages $6.3(22)$.
}

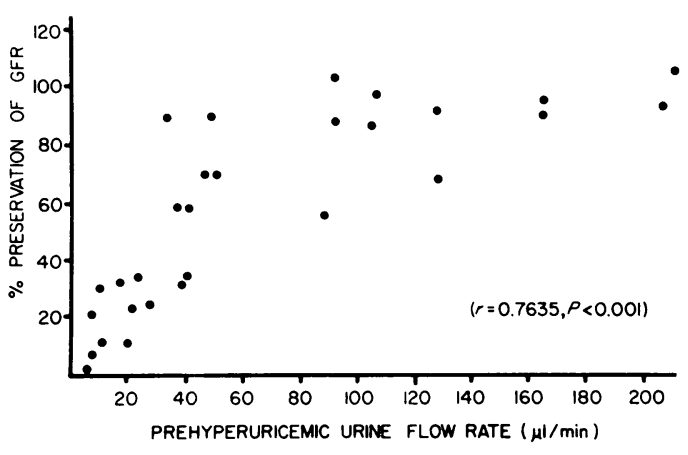

FIGURE 3 Relationship between percent preservation of initial glomerular filtration rate and the prehyperuricemic urine flow rate for all rats. Circles represent individual data from each animal studied.

the moderate diuresis of Groups II and III independent of the acid or alkaline nature of the urine. The untreated animals with low $\mathrm{V}$ had the most marked renal damage. When preurate $\mathrm{V}$ vs. percent preservation of initial GFR was plotted for all rats there was good correlation between these two parameters ( $r$ $=0.7635, P<0.001$ ) as shown in Fig. 3. The simplest explanation for the efficacy of high $\mathrm{V}$ to prevent urate and uric acid deposition in the kidney takes into account both chemical and mechanical factors. Previous work from our laboratory has confirmed that the major tubular site of urate deposition is the collecing duct (14). By inference from studies of renal tissue urate content during hyperuricemia, this is also the nephron segment of highest uric acid concentration $(18,20)$. The effect of high $\mathrm{V}$ would be to lower the concentration of urate within the collecting duct enhancing its solubility and to rapidly "flush" any precipitated urate material from this tubular segment. In support of this explanation is the finding that urinary urate concentration $\left(U_{\text {urate }}\right)$ was inversely related to the $\mathrm{V}$ and the percent protection of renal function $(r=0.6277, p<0.001)$. Although there is evidence that tubular fluid flow rates may have additional effects on urate handling by the kidney at normal plasma levels (21), no such information is presently available for the hyperuricemic state.

Uosm was high in the Group I animals and lower in the diuretic-treated and Brattleboro rats suggesting a relationship between prehyperuricemic Uosm and protection. There was a correlation between prehyperuricemia Uosm and percent preservation of initial GFR $(r=0.6774, P<0.001)$. However, initial Uosm was higher in Group IV than Group V (363 \pm 47 vs. $228 \pm 27 \mathrm{mosmol} /$ liter, $P<0.001$ ) despite similar levels of protection and was not different between Groups III and IV $(359 \pm 25$ vs. $363 \pm 47 \mathrm{mosmol} / \mathrm{liter}$, $P=$ NS) where impairment of kidney function was negligible in the former and nearly $50 \%$ in the latter. Moreover, if one compares solute excretion rates 
$($ Uosm $\times$ V) between Groups IV and V, the value for the former was more than twice that of the latter $(59.3 \pm 7.7$ vs. $24.3 \pm 2.9 \mathrm{mosmol} / \mathrm{min})$ suggesting that urine flow was a much more critical factor than solute excretion rate per se, since protection was similar.

It does not seem likely that the protective effect of the high-dose furosemide was related to a drug effect blocking tubular secretion rather than promoting a diuresis for two reasons. First, in the control period the clearance of urate exceeded that of inulin indicating a net secretion of urate into the tubule and thus actually increasing the tubular load of urate. Secondly, if the protective effect were specifically related to a direct drug effect, then there should not have been equal preservation of renal function in the Brattleboro rats that received no pharmacologic agents to promote diuresis.

Despite alkalinization of the urine to $7.9 \pm 0.2$ with acetazolamide and $\mathrm{NaHCO}_{3}$ in Group II rats, only partial preservation of kidney function was seen. Moreover, it is likely that this level of protection was due to the diuretic properties of acetazolamide rather than its alkalinizing effect, since identical renal function and morphologic results were seen in the lowdose furosemide group. These latter rats had preurate urine flow rates similar to those of acetazolamide $\mathrm{NaHCO}_{3}$-treated animals but a $\mathrm{UpH}$ of only $5.8 \pm 0.1$ which was not different from the untreated animals. In light of in vitro studies outlined above, it was surprising that urinary alkalinization was not more effective in preventing intrarenal deposits of urate. Klinenberg et al. (12) measured the solubility of uric acid in sodium phosphate buffer over an extensive range of $\mathrm{pH}$. At $\mathrm{pH} 7.9$, the mean level of $\mathrm{UpH}$ in Group II animals, uric acid solubility was $140 \mathrm{mg} / 100 \mathrm{ml}$. This value is more than twice the $\mathrm{U}_{\text {urate }}$ measured in Group III rats after urate infusion. Based on previous studies of fluid $\mathrm{pH}$ in various tubular segments during $\mathrm{NaHCO}_{3}$ loading (22), it is unlikely that $\mathrm{pH}$ was lower than that of the final urine at any site more proximal in the nephron. Thus, it is also unlikely that $\mathrm{UpH}$ was a falsely high estimate of hydrogen ion activity in the distal nephron where precipitation occurred. This lack of relationship between tubular fluid $\mathrm{pH}$ and urate deposition suggests that either the urine measurement did not accurately reflect the concentration of urate in the collecting duct system or that in vitro measurements of solubility and precipitation are not entirely applicable to urate precipitation phenomena in the tubular fluid environment. The report of Epstein and Pigeon (20) would argue against the former possibility. Even though they failed to show a good overall correlation between papillary and $U_{\text {urate }}$ at levels of hyperuricemia comparable to those in the present study, the mean papillary urate at most was only
$50 \%$ higher than $U_{\text {urate }}$. Based on these findings, papillary urate in the Group II rats still should have been below the in vitro measured solubility for $\mathrm{pH} \mathrm{7.9}$. Thus, it seems likely that within the kidney the relationship between urate deposition and tubular fluid $\mathrm{pH}$ is not so critical as in vitro studies would suggest.

The implications of these experiments are that maintenance of high distal nephron flow is the major factor in preventing acute urate nephropathy and that urine alkalinization is of minor importance. However, such conclusions should be drawn with considerable caution when applied to the clinical setting. There may be important species differences between rats and man that are not obviated by simply blocking uricase activity as was done in this model. Moreover, it is possible that $\mathrm{pH}$-related solubility may be a more critical pathogenetic factor at levels of filtered urate and at $\mathrm{pH}$ values not examined in this study. For these reasons it would be inappropriate to suggest that urine alkalinization be abandoned as a therapeutic modality in hyperuricemic acute renal failure. On the other hand, the data from this investigation do seem to indicate that tubular fluid flow is the most critical pathogenetic factor in this syndrome and that the primary method of its prevention is the establishment of high rates of urine flow.

\section{ACKNOWLEDGMENTS}

The authors wish to thank Ms. Susan Christie and Mr. Martin Kondreck for technical assistance, Ms. Dottie Goodman and Mrs. Daisy Rodarte for help with manuscript preparation, and Dr. Robert Schrier for his critical review of the work.

These experiments were supported by the National Institutes of Health (grant HL-18097) and Veterans Administration Research Funds.

\section{REFERENCES}

1. Merrill, D., and H. Jackson, Jr. 1943. The renal complications of leukemia. N. Engl. J. Med. 228: 271-276.

2. Frei, E., III, C. J. Bentzel, R. Rieselbach, and J. B. Block. 1963. Renal complications of neoplastic disease. J. Chronic Dis. 16: 757-776.

3. Kritzler, R. A. 1958. Anuria complicating the treatment of leukemia. Am. J. Med. 25: 532-538.

4. Weintraub, L. R., J. A. Penner, and M. C. Meyers. 1964. Acute uric acid nephropathy in leukemia. Report of a case treated with peritoneal dialysis. Arch. Intern. Med. 113: 111-114.

5. Handa, S. P. 1971. Acute renal failure in association with hyperuricemia: Its recovery with ethacrynic acid. South. Med. J. 64: 676-678.

6. Steinberg, S. M., M. A. Galen, J. M. Lazarus, E. G. Lowrie, C. L. Hampers, and N. Jaffe. 1975. Hemodialysis for acute anuric uric acid nephropathy. Am.J. Dis. Child. 129: 956-958.

7. Watts, R. W. E., P. J. Watkins, J. Q. Matthias, and D. A Gibbs. 1966. Allopurinol and acute uric acid nephropathy. Br. Med.J. 1: 205-208.

8. Kjellstrand, C. M., D. C. Campbell, II, B. von Hartitzsch, 
and T. J. Buselmeier. 1974. Hyperuricemic acute renal failure. Arch. Intern. Med. 133: 349-359.

9. Krakoff, I. H. 1966. Use of allopurinol in preventing hyperuricemia in leukemia and lymphoma. Cancer (Phila.). 19: 1489-1496.

10. Peters, J. P., and D. D. Van Slyke. 1946. Quantitative Clinical Chemistry. The Williams \& Wilkins Co., Baltimore. 2nd edition. $1041 \mathrm{pp}$.

11. Talbott, J. H. 1964. Gout. Grune \& Stratton, Inc., New York, 2nd edition. 261 pp.

12. Klinenberg, J. R., R. Bluestone, L. Schlosstein, J. Waisman, and M. W. Whitehouse. 1973. Urate deposition disease. How is it regulated and how can it be modified? Ann. Intern. Med. 78: 99-111.

13. Rieselbach, R. E., C. J. Bentzel, E. Cotlove, E. Frei, III, and E. J. Freireich. 1964. Uric acid excretion and renal function in the acute hyperuricemia of leukemia. Pathogenesis and therapy of uric acid nephropathy. Am. J. Med. 37: 872-884.

14. Conger, J. D., S. A. Falk, S. J. Guggenheim, and T. J. Burke. 1976. A micropuncture study of the early phase of acute urate nephropathy. J. Clin. Invest. 58: 681689.

15. Bartoli, E., J. D. Conger, and L. E. Earley. 1973. Effect of intraluminal flow on proximal tubular reabsorption. J. Clin. Invest. 52: 843-849.

16. Vurek, G. G., and S. E. Pegram. 1966. Fluorometric method for the determination of nanogram quantities of inulin. Anal. Biochem. 16: 409-419.

17. Conger, J. D., H. N. Rhoads, S. N. Christie, and T. J. Burke. 1975. A modification of the fluorescence method for micro-inulin determinations. Kidney Int. 8: 334-337.

18. Mudge, G. H. 1965. The renal tubular transport of urate. Arthritis Rheum. 8: 686-693.

19. Greger, R., F. Lang, and P. Deetjen. 1971. Handling of uric acid by the rat kidney. I. Microanalysis of uric acid in proximal tubular fluid. Pfluegers Arch. Eur. J. Physiol. 324: 279-287.

20. Epstein, F. H., and G. Pigeon. 1964. Experimental urate nephropathy: studies of the distribution of urate in renal tissue. Nephron. 1: 144-157.

21. Weinman, E. J., G. Eknoyan, and W. N. Suki. 1975. The influence of the extracellular fluid volume on the tubular reabsorption of uric acid. J. Clin. Invest. 55: 283-291.

22. Malnic, G., M. de Mello Aires, and G. Giebisch. 1972. Micropuncture study of renal tubular hydrogen ion transport in the rat. Am. J. Physiol. 222: 147-158. 